\title{
Unraveling the Leadership Dichotomy in the Classroom and Beyond
}

\author{
Leah M. Omilion-Hodges \\ Assistant Professor \\ School of Communication \\ Western Michigan University \\ Stacey M. B. Wieland \\ Associate Professor \\ Calvin College
}

\begin{abstract}
As teachers of leadership, we have noticed that our students often get "stuck" thinking about leadership in overly simplistic ways that dichotomize task and relationship-orientations, often resulting in overly simplistic understandings of leadership processes. In this reflective essay, we draw upon two approaches to leadership theory-leadership psychology and discursive leadership - to consider why the leadership dichotomy occurs and provide ideas for how leadership instructors might restructure and refocus their courses to help students transcend it to develop more reflexive, contextualized understandings of leadership. We suggest four ideas for innovating leadership pedagogy: 1) rethink the typical chronological organization, 2) challenge students to identify leadership myths, 3) engage students in applied leadership contexts, and 4) emphasize leadership as a communicative practice.
\end{abstract}

\section{Introduction}

As instructors of an undergraduate leadership course, we have found that traditional approaches to teaching leadership may actually hinder student comprehension (Robles, 2012). We have consistently noticed that students - despite being taught otherwise - are seduced by reductionist thinking about the practice of leadership. Yet, because students are often introduced to the lineage of leadership literature beginning with early studies that present task and relational elements of leading as distinct and focus strongly on individual leaders' traits, behaviors and styles, students are primed to interpret more contemporary and complex approaches through this bifurcation and with a strong individualism that infuses the way they practice and perceive the act of leading. Thus, after continually witnessing students experience difficulty in transcending the task/relational dichotomy, we wrote this essay to trace the roots of this reductionist thinking and to offer pedagogical and pragmatic alternatives. We suggest that by considering small changes to leadership pedagogy, we are able to better equip students to more carefully consider the dynamic and complex interdependence of leaders, followers, and situational factors. We argue that by starting courses with more sophisticated, current theories we will able to engage in more meaningful conversations about the way ways in which leadership is enacted in a variety of contexts, including helping students to thoughtfully consider the complex and distributed leadership process in their future organizations. In short, we are seeking to mitigate the outmoded theories and ideas imbued within early leadership literature because our discipline has come a long way from suggesting that we understand leadership as a construct from focusing 
exclusively on leaders and their behaviors.

We link this problem to the persistence of views that frame leadership as centrally concerned with either people or productivity; where such a view relies on extreme portrayals of leaders that polarize autocratic and democratic styles and obscure the gradients between. Moreover, early studies not only dichotomize task and relational components, but also anchor their central focus on the leader at the expense of followers. For example, one student wrote the following in-class reflection after learning about leadership styles and being asked to journal about any concerns they anticipated the styles approaches could infuse into their future organizational life:

I am still torn on whether I should be a task or interpersonal leader. Relationships are important, but it's hard to imagine you'll keep your job if you don't reach your goals. However, focusing all of my energy on task achievement is likely to hurt my relationship with followers.

Students such as this view their own leadership in dichotomous terms - presuming that task and relational elements of leadership are inherently distinct, mutually exclusive, and competing. This oversimplification presumably shapes how they perceive and practice leadership.

Thus, instead of thinking critically about the ways that concern for tasks and people might be integrated in the practice of leadership, we have routinely found that students fall back on superficial explanations, directing their attention to either people or tasks. As such, we suggest ideas for transforming leadership pedagogy to avoid the sedimentation of traditional, static models and hope that the concerns discussed in this paper will also spur helpful reflection among other educators. Specifically, this paper suggests that structuring course material historically (as the authors previously did) may lead students to get trapped in early theories that offer overly simple interpretations that dichotomize task and relational elements of leading and that are then mapped onto autocratic and democratic styles, further inflating the central focus on the leader. Thus, even when students are presented with situational leadership - which advises that leaders adapt their behaviors to the needs of a given situation - and other more contemporary approaches that depart in significant ways from classic dichotomous thinking, students have already been primed to interpret the art of leading in terms of two separate foci: tasks and relationships. Similarly, students then have difficulty with more complex approaches that complicate the intersection of tasks and relationships, making it difficult to understand that leadership is about more than individuals in positions of authority.

In this paper, we trace the origins of the leadership dichotomy to foundational leadership studies and demonstrate how these early conceptualizations impact present day leadership instruction. We employ two perspectives-leadership psychology and discursive leadership (Fairhurst, 2007) - to explore why the dichotomy persists and how we might enhance leadership pedagogy to move students beyond such simplistic thinking. Both critiques ultimately conclude that a renewed focus on leadership and how it is enacted through communication in nuanced contexts helps transcend the dichotomization of tasks and relationships. When we focus on leadership as a communicative practice, it becomes impossible to untangle the task and the relational elements: "Communication is the primary tool leaders use to bring people together to 
affect the performance of a group or an organization" (Gamble \& Gamble, 2013, p. 10; see also Hall \& Lord, 1995; Holladay \& Coombs, 1993). We argue that helping students understand the nuances of enacting leadership will make them more apt to consider the complexities of leading and also be better prepared to adaptively lead (or follow) successfully. In this sense, the goal shifts to emphasize understanding and critical thinking so that leaders and followers are able to successfully enact leadership in a situated context.

This analysis suggests that perhaps the most common ways of teaching leadership, namely the chronological approach that immediately commences with studies that detail leadership through tasks and people (i.e., The University of Michigan and The Ohio State University studies) may stunt students' ability to think more deeply about leader traits, behaviors, styles, and contexts. Thus, even though the chronological approach may help to lay the foundation for leadership literature, we continue to witness unintended consequences that hinder student comprehension. To clarify, we are not suggesting that faculty discard the rich lineage of leadership literature; rather, we call upon educators to think differently about the ways in which we introduce and guide students through the material and how we as educators challenge students to apply these early theories. We conclude by providing alternatives for leadership pedagogy that seek to avoid narrow interpretations of the practice of leadership by providing students with a contextualized view that will better prepare them for professional careers (Tuleja \& Greenhalgh, 2008).

\section{Challenging the Leadership Dichotomy: A Leadership Psychology Perspective}

The first critique considers the leadership dichotomy from a traditional social scientific perspective, which has also been referred to as leadership psychology (Fairhurst, 2007). From this perspective, leadership is "human communication, which modifies the attitudes and behaviors of others in order to meet shared group goals and needs" (Hackman \& Johnson, 2013, p. 11). We acknowledge that even though literature has moved far beyond classic approaches that anchor their focus in tasks and people, students still have difficulty transitioning to more complex approaches because they have been primed to view leadership through early dichotomous lenses. Classic approaches also assume a strong individualist approach to leading, where the legitimate authority associated with formal leadership positions outshines the complexities associated with more contemporary approaches that consider the context in which leadership occurs. Thus, we argue that dichotomizing task and relationship elements oversimplifies the practice of leadership by generalizing about leader behaviors and contexts. Dichotomization also leads to the portrayal of leaders monolithically as either democratic or autocratic (Hackman \& Johnson, 2013). Therefore, the many ways that concern for tasks and people can influence leadership practice are often overlooked. As a result, it promotes a shallow understanding that obscures the richness and depth of leadership, concealing the often messy (Dennis et al., 2010), contextualized (Liden \& Antonakis, 2009) work of leadership. Because leaders of complex organizations must enact both concern for tasks and people in a variety of ways, we argue that instead of emphasizing a particular style over another, instructors of leadership should help students be aware of and attuned to contextual factors and adapt to nuanced leadership contexts. We are not suggesting that leadership instructors are not already doing so, but we recommend that educators engage students in such conversations from the onset to prepare them for more realistic and nuanced understandings of the complexity of leading, such 
as considering follower needs and maturity and situational factors such as financial and time constraints. If instructors wait to discuss contextual factors after presenting classic approaches that dichotomize task and relationship demands or emphasize the individualism of the leader, then students may continue to revert to these superficial subscriptions of what it means to lead.

Classic Conceptualizations: The Root of Dichotomous Thinking. The following section draws upon classical leadership theories to consider how the task and relational dichotomy emerged and why it persists. Specifically, we argue that early approaches to leadership that present simplistic dichotomies get carried into later conceptualizations of leadership as a result of chronological presentation of leadership theory. While more recent approaches such as transformational and authentic leadership are multifaceted and complex, we have found that students often regress to a shallow understanding due in part to the outdated, simplistic approaches they learn initially. Likewise, because task and relational styles are quickly mapped onto autocratic and democratic styles, students infer that leadership is enacted only by those who possess legitimate authority. After tracing the roots of dichotomous thinking, we propose the importance of focusing students more on leadership contexts, rather than on individual leaders.

Early leadership research including the University of Michigan (Katz et al., 1953) and The Ohio State University (Hemphill, 1950; Fleishman, 1953) studies presented task and relational elements as fundamental components of leadership, but did so in a way that positions them as distinct. First, the Michigan Leadership Studies (Katz et al. 1951), presented leader behavior on a single continuum that ranged from employee-oriented to production-oriented presenting a polarized view of leader behavior that markedly separates relationships with followers from task needs (Katz et al.). Researchers at Ohio State (Hemphill; Fleishman) later presented two dimensions - initiating structure (goal attainment) and consideration (relationships) - that framed task and relational foci independently. Supervisors could be high on one dimension without it necessarily detracting from the other (Fleishman). While this perspective emphasizes the importance of simultaneously attending to tasks and relationships, it retains a view of them as divergent, which perpetuates a two-dimensional interpretation of leadership that continues to inform instruction (Hackman \& Johnson, 2013) and scholarship (e.g., Judge, Piccolo, \& Illies, 2004). These early studies bring about a narrow understanding of how leadership functions in practice by glossing over the messiness of leading (Denis, Langley, \& Rouleau, 2010) and by focusing exclusively on the leader at the expense of followers and the situation. Despite the limitations of classical approaches, students are generally introduced to classical approaches first because of the traditional chronological makeup of popular textbooks and common approaches to organizing class material. As a result, students come to see task and relational elements as mutually exclusive, competing elements of leadership.

The dichotomous framing of people/consideration and tasks/initiating structure found in classical leadership studies at the University of Michigan and Ohio State still persists in newer conceptualizations of leadership (e.g., Madlock, 2008; Van Slyke \& Alexander, 2006). For example, Madlock examined leader task and relational styles separately to explore their individual effects on employee job and communication satisfaction. Thus, this trend may be one of the reasons that students get "stuck" in the misconception that task and relational needs are separate and at-odds, thereby forcing leaders to choose one over the other. However, the effects 
of task-oriented and relationship-oriented behaviors are intertwined: A high level of relationshiporiented behavior may not improve performance unless the leader also uses appropriate taskoriented behaviors, and the optimal pattern of specific task and relations behaviors depends on the situation or context (Yukl, 2011). We now discuss how task and relational behavior pervades the styles approach to leadership — a classic approach traditionally taught in the early weeks of a survey leadership course presumably because it often makes up the first few chapters of popular leadership texts (e.g., Hackman \& Johnson, 2013; Northouse, 2010).

The Styles Approach: Retaining the Separation. A bifurcated view of the task and relational elements of leadership also pervades scholarship from the styles approach. By example, a popular leadership communication textbook conflates concern with task with autocratic leadership and concern with relationships with democratic leadership: "The task leader is often highly authoritarian. In contrast, the interpersonal leader is concerned with relationships. This style, similar to the democratic style, emphasizes teamwork, cooperation, and supportive communication" (Hackman \& Johnson, 2013, p. 48). Given this, it is not surprising that an undergraduate student wrote the following reflection after learning about the styles approach:

After this [lecture on leadership styles], I find that leading is easier that I thought. I believe in a democracy and in giving everyone a voice. I also care about people and want to make sure that everyone is heard. That means that I'm a democratic leader because autocratic leaders care mostly about their own voice and completing tasks.

Presenting leadership as an either/or - either the leader excels at cultivating leader-member relationships or the leader successfully orients to tasks - is often implied with the use of democratic or autocratic labels. These archetypes provide a shallow means of understanding leadership that fails to account for the multifaceted and adaptive practice of leadership.

The conflation of task and relationship orientation with autocratic and democratic labels is not a new problem. Twenty-five years ago, Bass (1990, p. 413) contended that leadership theories are often oversimplified to the point where they could be understood on a single continuum ranging from autocratic to democratic. The autocratic cluster (Bass, p. 413) consists of authoritarian, directive, Theory X, coercive, production centered, production oriented, leaderderived decision making, initiating structure, goal emphasis, task oriented, and performance concern. Leadership theories and conceptualizations considered to be democratic in nature include: consideration, democratic, consultative, consensual, employee centered, people oriented, relations focused, interaction facilitating, relations emphasis, group-derived decision making, and Theory $\mathrm{Y}$.

This dichotomization of task and relational elements as they are applied to autocratic and democratic styles can also be seen in the way that leadership is presented in the Leadership Grid (Blake \& Mouton, 1964; Blake \& McCanse, 1991). Utilizing two axes, the Leadership Grid describes five distinct variations of leadership based on varying degrees of concern for people and concern for production, indicating that whenever leadership occurs there is a blending of both task and relationship behaviors. As a result, Blake and McCanse do not portray democratic leaders as only relationally focused; in fact, they refer to democratic leaders explicitly in describing the "high/high" or 9, 9 Team Management leader. While this acknowledges a 
blending of task and relational concerns, the way autocratic leaders are typified within the model preserves a dichotomous view. Termed Authority Compliance (Blake \& McCanse), autocratic leaders have a high concern with production and low concern for people. They are seen as promoting efficient operations that "result from arranging conditions of work in such a way that human elements interfere to a minimum degree," insinuating that autocratic leaders operate in a strategic, calculated manner to the detriment of their group, which helps to explain why they are often portrayed as "villains" (Warrick, 1985 p. 169).

Though the Leadership Grid (Blake \& McCanse, 1991) moves beyond equating both of the styles as an either/or, it is problematic to see the combination of task and relational concerns in a monolithic way such that it is associated only with the sharing of authority enacted through Team Management leaders. What it means to be high in task focus and high in relationship focus are thus interpreted narrowly, where this portrayal also propagates the emphasis on the individual leader and equates leading only with the sharing of authority. For example, leaders who are highly task-focused may differ from one another in terms of how they approach decision-making and distributing authority. Concern for production does not necessarily mean someone is an autocratic leader who wears "serious expressions" as they work to complete tasks (Humphrey, 2002 , p. 494). Instead, it may be more helpful to understand concern for production as the extent to which a leader leverages their collective resources, including followers, in order to accomplish group and organizational goals. Moreover, leaders who are relationally inclined may also differ from one another in terms of how they relate to followers. Concern for people does not necessarily mean that leaders "wear friendly expressions" putting people above the task (Humphrey, p. 494). Alternatively, it may be more beneficial to understand a leader's concern for people as the extent to which they value people and attend to their needs and concerns in relation to the organization, where leaders are likely to employ different methods to do so. One leader may demonstrate concern for people by delegating decision-making authority to followers to empower them (Sprietzer, De Janasz, \& Quinn, 1999) whereas others may exhibit concern for followers by sheltering them from organizational politics or backlash (Chaleff, 2009). To that end, we argue that it is possible for both leaders who direct authority and those who distribute authority to have high regard for both tasks and people. Moreover, leaders who simultaneously orient to both tasks and followers are likely to differ considerably in the ways that they distribute authority. As a result, the way that democratic and autocratic styles are presented in the Leadership Grid overly simplifies each and perpetuates the dichotomization of both task (e.g., initiating structure, concern for production) and relationship (e.g., consideration, concern for people) orientations into democratic and autocratic styles.

Modern Leadership Research: Operationalizing Archetypes. Leadership dichotomies are not confined to classic conceptualizations: They still inform research and pedagogy today (Uhl-Bien \& Marion, 2011). Before discussing how these archetypes continue to be operationalized in studies of leadership, we want to clarify that we are not suggesting that educators deny foundational leadership theories; rather, we are calling on fellow instructors to think differently about how we challenge students to question these early theories and principles. Correspondingly, we also encourage leadership scholars to continue to work on more complex and contextually-focused scholarship. Thus, our focus is on how educators can help students move beyond dichotomies and embrace the nuances and complexities of practicing leadership. 
In examining leadership behavior in empirical studies, researchers (e.g., Bird \& Wang, 2013; Fletcher \& Roberts, 2013; Morrisette \& Oberman, 2013; Ruiz, Wang, \& Hamlin, 2013; Zydziunaite, Lepaite, \& Suominen, 2013) commonly conceptualize leadership by operationalizing traditionally democratic (e.g., soliciting feedback) and autocratic (e.g., unilateral decision-making) styles instead of focusing on how individuals employ various skills in diverse situations. More problematic, perhaps, is that in operationalizing leadership styles in the laboratory, scholars may rely on extreme views of autocratic and democratic leaders, where the potency of the style is often inflated beyond realistic leadership behavior (Foels, Driskell, Mullen, \& Salas, 2000). We do not wish to discredit or discourage laboratory studies; however, researchers must remain cognizant that while using polarized leadership styles and inflated leadership behaviors may indicate larger effects between conditions, studies that rely on polarizations further dichotomize task and relational elements and reduce leadership to stock categories (e.g., Bhatti, Maitlo, Shaikh, Hashmi, \& Shaikh, 2012; Schoel, Bluernke, Mueller, \& Stahlberg, 2011; Terzi, 2011). Our concern is that when students' understanding of leadership is shaped by this dichotomy, it leads to weak and ineffective leadership practices that may translate into the workplace. Therefore, we suggest shifting the attention from the person who is enacting leadership to the context so that students have a more nuanced and multifaceted approach to enacting and interpreting leadership.

In summary, the first critique focused on why students get "stuck" in leadership styles and then continue to conceptualize them in relation to task and relationship orientations. We argued that the assumption that tasks and relationships are separable and opposed has been perpetuated through classical approaches as well as the conflation of autocratic style with taskorientation (at the expense of relationships) and democratic style with people-focus (at the expense of organizational goals and tasks). These oversimplifications minimize the multiple ways that concern for tasks and relationships can be enacted simultaneously in leadership practice. In the conclusion, we suggest that by emphasizing leadership contexts and providing students with opportunities to engage applied organizational leadership situations, students will better understand the complex interdependencies of task and relational elements in the practice of leadership.

Contextualizing Leadership to Avoid the Leadership Dichotomy. Rather than framing leadership on a single continuum from task to relational that conceals the intricacies of the enactment of leadership, we suggest that those teaching leadership should focus more on the leadership context than the traits or styles of the individual leader. When students of leadership are equipped to read contextual cues, they will be less likely to rely on overly simplistic task/relational bifurcations. Fortunately, several models consider how contextual factors influence the practice of leadership. For example, by prompting leaders to consider internal and external factors within themselves, their followers and the situation, Tannenbaum and Schmidt's (1973) model stresses the role of context imbued within leadership as leaders must consider personal style inclinations while balancing relational, task, and situational elements before enacting leadership. Yukl (2010) also considers the role of critically understanding the context of leadership. Yukl suggests that to optimally adapt to changing events, leaders must employ and enact intelligence and reasoning skills, complex problem solving skills, divergent thinking skills, creativity, metacognitive skills, decision making skills, cognitive complexity and flexibility, administration skills, self and unit regulation skills, tolerance for ambiguity, openness, emotional 
stability, resilience, and conscientiousness (p. 14). Like Tannenbaum and Schmidt, Yukl emphasizes the role of context while highlighting the profound depth of the skills and abilities leaders must possess when they read and react to leadership contexts.

Yukl's (2010) perspective - and the one we advocate for - goes beyond traditional situational leadership by providing a more dynamic and situated view of leadership contexts. Some (Yip \& Raelin, 2012) suggest that students may interpret situational leadership as guidelines for developing one appropriate response for any given situation. Situational leadership theories often seek to provide prescriptive, predictive guidelines for the enactment of leadership, thus implying - as do classic leadership theories (i.e., Leadership Grid) - that there is one "right" solution for any particular type of leadership problem. Because of these concerns, instead of using situational leadership as a panacea we urge instructors to prepare students further by helping them to consider the plethora of contextual cues within the dyadic, group, and organizational levels such as time pressures, economic constraints, group dynamics, and leader preferences. Thus, we echo earlier calls (Hackman \& Johnson, 2013) that have suggested that situational leadership (Hersey \& Blanchard, 1982) be utilized as a teaching tool that encourages students to consider the role of follower readiness in a leader's success as opposed to a prescriptive theory (e.g., the Leadership Grid) for leading in applied contexts. In short, students need to understand leadership as it is situated in applied contexts (Stohl \& Putnam, 1990).

\section{Challenging the Leadership Dichotomy: A Discursive Leadership Perspective}

The second analysis uses a discursive leadership lens to argue that the dichotomous language of leadership - how we talk about leadership tasks, relationships, styles, and situations - reflects dominant ways of framing leadership. These interpretative repertoires perpetuate problematic assumptions about leaders and leadership contexts that conceal the social construction of leadership. In this section we draw upon discursive leadership to consider the problematic implications of dominant ways of framing leadership. This approach offers a more radical critique than the first by arguing that the ways that leadership has been framed perpetuates an individualized view of leadership that essentializes (treats as natural and objective) both the leader and the context and downplays the role of communication in constituting leadership and its context. In contrast, a discursive approach defines leadership as occurring "when ideas expressed in talk or action are recognized by others as capable of progressing tasks or problems which are important to them" (Robinson, 2001, p. 93, as cited in Fairhurst, 2007). From this perspective, leadership is negotiated in relationship with various actors in the leadership context (Fairhurst \& Uhl-Bien, 2012), which is socially constructed through communication. As a result, the second critique suggests the need to reflexively understand the ways that leadership and the leadership context are constructed through communication, resulting in fluid, multiple, and sometimes competing interpretations. Understanding is the chief goal, which enables a more nuanced sense of how leadership functions in situ and how leadership actors can best facilitate organizing and leadership. From this view, reflexivity - reflection aimed at understanding how our starting assumptions and initial framing of an issue shapes our conclusions about it - becomes central to the communicative practice of leadership. 
Based on discursive leadership (Fairhurst, 2007; 2008; 2011), our second critique challenges foundational objectivist assumptions that dominate leadership scholarship and teaching and draws upon social constructionism to reframe leadership as communicative (Collison, 2011; Fairhurst, 2007, 2011; Grint, 2000; Western, 2008). Discursive leadership considers leadership as enacted and constructed through discourse and emphasizes the ways that leadership is represented, negotiated and constituted through talk and text (Fairhurst \& Grant, 2010). This perspective holds that language constructs - rather than simply reflects - social realities. Thus, language does not objectively describe already-existing social realities, but instead constitutes social realities by framing them in particular ways (Fairhurst, 2009). It follows that the ways we talk about leadership and leaders shape-rather than simply reflectleadership and leaders. This occurs not only through commonplace conversations, but also through teaching and scholarship: Those studying and teaching leadership participate in the social construction process, actively shaping the phenomenon of leadership. In this critique we use discursive leadership to consider how the ways we talk about leadership in terms of tasks, relationships, styles, and situations constitutes leadership in problematic ways.

The Styles Discourse as an Interpretative Repertoire. From a discursive leadership perspective the social construction of reality is shaped by Discourses, or relatively sedimented cultural ideologies drawn upon in everyday conversations that shape interpretations (Alvesson and Kärreman, 2000; the upper-case D is used to indicate broader, macro-Discourses as opposed to local interaction which is referred to with a lower-case d). Potter and Wetherell (1987) explain that Discourses serve as interpretative repertoires, "a lexicon or register of terms and metaphors drawn upon to characterize and evaluate actions and events" (p. 138). Basically, interpretative repertoires are stock ways of talking about something that shape how we interpret that phenomenon and are manifest in "terminology, metaphors, habitual forms of argument, familiar story themes, and so on" (Fairhurst \& Grant, 2010, p. 181). Interpretative repertoires shape how scholars, practitioners, educators, and students talk about and Discursively construct leadership.

We suggest that the ways that scholars, instructors and students talk about tasks, relationships and styles — what we will call the Styles Discourse - reflect and constitute broader interpretative repertoires that construct leadership in problematic ways. We identify two problematic assumptions that these interpretative repertoires perpetuate: 1) leaders have a high degree of individual agency; and 2) leadership contexts can be objectively described and predicted. We demonstrate how the Styles Discourse perpetuates both of these assumptions and argue that this oversimplifies the messy and complex socially constructed realities of leadership practice.

The Styles Discourse and Leader Agency. One assumption that is perpetuated through the interpretative repertoire of leadership styles is that leaders have a high degree of individual agency in the leadership process. This assumption can be seen in the primary focus of the styles perspective on the individual leader. Within the styles perspective followers are notably absent (Kellerman, 2008). This absence in-and-of-itself overinflates the importance of and agency of the leader. Later approaches, such as the situational perspective (e.g. Hersey \& Blanchard, 1982), incorporate followers into leadership models in order to help leaders determine which style to use in a given situation. By including followers, the situational approach moves away from the essentialist assumptions described above by claiming that leaders can adapt and perform in ways 
that stretch them beyond their dispositions. However, by encouraging leaders to use styles adaptively to gain compliance from followers, followers are framed as passive and manipulable (Kellerman). This view of followers constructs leaders as having an inordinate degree of agency and minimizes the agency of followers, resulting in a view of leadership communication as more-or-less a one-way process dictated by the leader. Such approaches imply, for example, that "leaders determine a vision without needing much in the way of feedback" (Tourish \& Barge, 2010, p. 324). Although attention to followership is increasing, followers continue to be framed as having a dichotomous relationship with leaders and as being of secondary importance (Bligh, 2011).

In contrast, discursive leadership emphasizes that leadership is negotiated between various actors (Fairhurst \& Uhl-Bien, 2012). As Grint (2000) notes, "Leadership is not simply about leaders. Leadership is essentially a social phenomenon: without followers, there are no leaders" (p. 6). This perspective sees organizational contexts as intersubjectively constituted by various organizational members through the ongoing process of communication (Fairhurst, 2007). Discursive leadership stresses the social process rather than the individual who is in a position of authority and focuses on leadership rather than leaders (Fairhurst \& Uhl-Bien). Fairhurst suggests that when we do discuss individuals who enact leadership, we should refer to them as "leadership actors" rather than leaders in order to acknowledge that various members of the organization — not just those in formal positions of authority - enact leadership. Complexity leadership - which views leadership as a function of systems - also questions the overemphasis on individual agency in the leadership literature (Uhl-Bien \& Mario, 2007). Shifting away from individual agents to seeing leadership as distributed and enacted jointly emphasizes the importance of understanding the social context — which includes the construction of both tasks and relationships (as well as many other things) — in order to understand leadership processes. Rather than seeing such elements of the leadership context as variables that can be objectively isolated, a discursive leadership perspective sees them as constituted through interaction and intricately wound up with one another, making them messy and difficult to pull apart.

The Styles Discourse and the Essentialization of the Leadership Context. The second way that the interpretative repertoire of leadership styles constructs leadership problematically is by essentializing and objectifying the leadership context as singular and having a stable and enduring set of attributes. Perspectives that see leaders as adaptable and capable of performing various styles construct the leadership situation objectively and seek to predict and control the outcome of particular leadership behaviors. The belief is that if researchers can isolate and document particular details about the context - for example, the type of followers, type of task, and type of leader - they will be able to predict which leadership behaviors will be effective in achieving a desired result. The Tannenbaum and Schmidt (1973) model, cited earlier in this paper as an example of a model that goes beyond the bifurcation of tasks and relationships, is a good example of this interpretative repertoire in action.

Tannenbaum and Schmidt (1973) suggest that answering the question of how one should lead should depend on "forces in" the manager, subordinates and situation. By using that language, Tannenbaum and Schmidt not only essentialize the leader (how a leader acts "will be influenced greatly by the many forces operating within his own personality," p. 6) and followers ("each employee, like themselves, is influenced by many personality variables," p. 7), but also 
construct the leadership situation as objectively describable and predictable: "certain characteristics of the general situation will also affect the manager's behavior. Among the more critical environmental pressures... are those which stem from the organization, the work group, the nature of the problem, and the pressures of time" (pp.7-8). Such deterministic languagelabeling them as "forces" and "pressures" that are in the environment-constructs leadership contexts as objectively existing, singularly and statically, for leaders to respond to. This belief that organizational contexts exist to be encountered by leaders can lead to overly simplistic views of leadership contexts and how particular behaviors will impact them. Fairhurst (2007) agrees that "conceptualizing the organization as an already formed entity, instead of one that is in a state of becoming," is a faulty assumption (p. 23).

Seeing organizations as in a state of becoming acknowledges that they are created, maintained and transformed through ongoing processes of communication (Fairhurst, 2009). Further, it sees organizational contexts as multiple and shaped by various interpretations. As Grint, (2000) writes, "what counts as a 'situation' and what counts as the 'appropriate' way of leading in that situation are interpretive and contestable issues, not issues that can be decided by objective criteria" (p. 3). As a result of this orientation, discursive leadership moves us away from a focus on the leader and the leader's behaviors to instead seek to understand organizational context as evolving and contested. By pointing attention to the ongoing process of organizing as co-constructed, this perspective highlights the need to develop a more nuanced and messy understanding of the practice of leadership and how it is enacted in any particular socially constructed context. Such a nuanced understanding encourages students to move away from simplistic either/or views of leaders as focusing on task or relationships to instead see the complex and evolving ways that tasks and relationships are negotiated and interpreted by various organizational actors.

By highlighting how these assumptions are perpetuated through the interpretative repertoire of leadership tasks, relationships, and styles, we have illustrated that this Discourse overemphasizes the agency of the leader and essentializes the leadership context. We have argued that such constructions limit our ability to understand leadership in ways that enable the effective practice of leadership in nuanced, complex, and contested leadership contexts. The central root of the problem is that the social constructions of leadership and leadership contexts that result from the dominant Discourses of leadership do not enable understanding of socially constructed leadership contexts that are messy, changing, and interpreted variously.

Emphasizing Reflexivity to Avoid the Leadership Dichotomy. A discursive leadership perspective suggests that leadership is messy and situated-“a highly contextualized and situated activity that is more about making wise choices in the moment than following a fixed a priori script" (Tourish \& Barge, 2010, p. 328). Seeking to describe and explainhow leadership actors and the leadership context are constructed through communication is key to enabling situated (inter)actions. Reflexivity can be central to achieving such an understanding (Barge, 2004). This perspective emphasizes the need for leadership actors to make informed and improvised responses to complex, contested, and changing leadership contexts. Critical thinking skills and interpretive abilities - such as perspective taking and the framing of reality - can be especially important for helping students understand how to respond to the complexities of particular leadership contexts. 


\section{Implications and Conclusion}

While the two lenses - leadership psychology and discursive leadership (Fairhurst, 2007) — we used to critique the leadership dichotomy are quite different, we see three significant overlaps in their critiques. First, both critiques conclude that students become seduced by overly naïve and simplistic conceptualizations of leadership. Second, both critiques raise concerns about the strong individualism that infuses the ways we study and talk about the practice of leadership. Finally, both critiques point to contextualizing leadership in messy and unique contexts as key to overcoming dichotomous, simplistic and individualistic conceptualizations of leadership. We now highlight several ideas for altering leadership pedagogy that respond to the concerns raised in the critiques above.

First, because both critiques indicate that students often fail to move beyond the neat and simplistic conceptualizations found in early leadership theories, we suggest the need to rethink the chronological organization of leadership courses. Popular leadership textbooks such as Hackman and Johnson (2013) and Northouse (2010), which are widely adopted and successfully reprinted (Sage, personal email), organize the material historically. It seems fair to presume that instructors using textbooks organized historically arrange their courses similarly.

While we do not want to discredit these prevalent textbooks or degrade the importance of understanding the evolution of the field, we suggest that presenting leadership historically may preclude a deeper and more substantive understanding of leadership because of the dichotomization of task and relationship elements and the strong focus on leader agency in early leadership theories. Our experiences suggest that students become entrenched in the assumptions of early models and use a dichotomous lens to interpret and frame subsequent approaches and conceptualizations. We suspect that this is also facilitated by the ways that early theories reflect quotidian views of leadership. In short, students have a hard time transcending the simplistic views of early theories.

Thus, rather than starting with the earliest theories of leadership, we suggest that instructors instead organize leadership courses topically, introducing state-of-the-art leadership theories related to each topic first. While historical accounts of leadership belong in any undergraduate survey course, instructors can help students gain an understanding of the progression of thought in the field by situating state-of-the-art theories within the historical context out of which they emerged. We believe that rethinking the chronological organization of course content would help students embrace leadership in its complexity rather than adopting overly simplistic understandings. For example, in an attempt to help students rise above the dichotomous view, one of the authors restructured her course to begin with a weeklong discussion of followership. In doing so, not only was the author able to frame leadership contextually and discuss the role and rights of followers, but also bring in additional complex leadership theories such as leader-member exchange (LMX). Students in this particular class demonstrated a deep ability to engage the variety of ways that concern for people and tasks are intertwined within complex, dynamic organizations. By beginning with more recent, complex theories, we believe that students will be better positioned to become adept surveyors of nuanced leadership contexts as these theories rest on leaders' ability to engage, adapt, motivate, and develop followers. Such a restructuring would help students to think more critically about the 
spaces and contexts in which leadership emerges and occurs as well as the fundamental role of communication. Moreover, this nuanced view of leadership will better equip students to break away from a one-size fits all view of leadership that "does not fully capture the experience of doing leadership as a practical activity in complex organizations" that are dynamic and unique (Denis et al., 2010, p. 67). Instead of emphasizing rigid guidelines and "right answers," we suggest that instructors stress that contexts vary considerably and that leaders need to tune into and adapt to those nuances. With this contextual focus, students are more apt to practice and perceive leadership in its complexity.

A second implication for leadership pedagogy is the importance of identifying and explicitly discussing with students myths that dominate popular conceptions of leadership and overemphasize individual leader agency. For example, we talk at length with our students about the myth of the leader as hero (and its converse, as scapegoat) as problematic in that it perpetuates an overly individualistic understanding of leading. Others have also noted concern in continuing to work from the perspective that "leaders are exceptional individuals" (Gronn, 2011, p. 438) at the expense of considering how they must work within groups and organizational structures to achieve goals. Such conversations invite students to think critically about the limits of leader agency and the complexities of leadership as a social, relational practice. This is in line with calls to shift attention from a single individual to consider leadership as a process that more than one organizational member participates in at any given time (Charlesworth, 2004).

A third implication for leadership pedagogy is the importance of student engagement of situated leadership contexts. As mentioned in the conclusion to the first critique, rather than talking about leadership more generally, we encourage those teaching leadership to help students experience specific leadership contexts so that they are prepared to respond and improvise. Those teaching leadership should understand their task as helping students develop understanding and reflexivity to enable informed yet improvised responses to complex, contested, and changing leadership contexts. This can be done through various methods, including incorporating realistic and detailed case studies into the classroom and immersing students in the field through projects that require participant-observation and in-depth interviewing, and by integrating role playing into the classroom setting and assigning projects that require students to engage leaders and organizations through participant-observation and interviewing. Moreover, this suggestion aligns with others who suggest leadership education should incorporate fundamental academic knowledge and skills, interpersonal and conceptual skills, and practical development and learning mechanisms (Elmuti et al., 2005, p.1026).

A fourth implication for leadership pedagogy is the importance of widening students' scope beyond leadership to develop a deeper understanding of leadership as communicative. This is especially important because traditional leadership theories do not adequately account for communication (Fairhurst, 2007). Similarly, leadership textbooks generally minimize communication; only three leadership textbooks emphasize the communicative elements of leadership (Barrett, 2014; Gamble \& Gamble, 2013; Hackman \& Johnson, 2013). As a result, communication skills are underemphasized in leadership courses. As we noted earlier in the second critique, viewing leadership as a communicative practice further helps to emphasize the interdependence of task and relational elements as they are interwoven communicatively. Thus, helping students understand leadership as communicative will make them more apt to perceive 
the complexities of leading and also be better prepared to adaptively lead (or follow) successfully. Students should be taught to be reflective individuals with a wide repertoire of communicative competencies such as listening, adapting messages for an audience, persuading, taking the perspective of another, negotiating, decision-making, resolving conflict, speaking, and writing. Such skills will help students to read and adapt to a multitude of leadership contexts. In this sense, we believe helping students to understand the importance of getting to know others as individuals will assist them in cultivating greater reflexivity where they will be able to think more critically about the implications of their words and actions within the group and organizational context. Similarly, focus on developing these communicative competencies will better prepare students as they ebb and flow between leader and follower roles within their groups, teams, and organizations.

Overall, this paper highlights the need to continue to reflect upon and evolve in terms of how we teach leadership as well as the benefit of using various lenses to guide leadership pedagogy. This paper contributes to leadership scholarship and pedagogy by drawing connections between leadership scholarship and the subsequent perception and practice of leadership. We hope that it induces further conversation and reflection about how instructors can better prepare students to understand leadership holistically, contextually and communicatively.

\section{References}

Alvesson, M., \& Kärreman, D. (2000). Varieties of discourse: On the study of organizations through discourse analysis. Human Relations, 53(9), 1125-1149. doi:10.1177/0018726700539002

Barrett, D.J. (2014). Leadership communication (4 ${ }^{\text {th }}$ ed.). New York, NY: McGraw-Hill.

Barge, J. K. (2004). Reflexivity and managerial practice. Communication Monographs, 71(1), 70-96. doi:10.1080/03634520410001691465

Bass, B.M. (1990). From transactional to transformational leadership: Learning to share the vision. Organizational Dynamics, 18, 19-31.doi:10.1016/0090-2616(90)90061-S

Bhatti, N., Maitlo, G.M., Shaikh, N., Hashmi, M.A., Shaikh, F. (2012). The impact of autocratic and democratic leadership style on job satisfaction. International Business Research, 5 (2), 192-201. doi: 10.5539/ibr.v5n2p192

Bird, J. J., \& Wang, C. (2013). Superintendents describe their leadership styles Implications for practice. Management in Education, 27(1), 14-18. doi: 10.1177/0892020612459287

Blake, R.R., \& McCanse, A.A. (1991). Leadership dilemmas-grid solutions. Houston, TX: Gulf Publishing.

Blake, R.R., \& Mouton, J. S. (1964). The managerial grid. Houston, TX: Gulf Publishing. 
Bligh, M. C. (2011). Followership and follower-centred approaches. In A. Bryman, D. Collinson, K. Grint, B. Jackson \& M. Uhl-Bien (Eds.), The Sage Handbook of Leadership (pp. 425436). London, England: Sage.

Chaleff, I. (2009). The courageous follower (2nd ed). San Francisco, CA: Berrett-Koehler.

Charlesworth, R. (2004). Shakespeare the coach. Sydney, Australia: Pan Macmillan.

Collinson, D. (2011). Critical leadership studies. In A. Bryman, D. Collinson, K. Grint, B. Jackson \& M. Uhl-Bien (Eds.), The Sage Handbook of Leadership (pp. 181-194). London, England: Sage.

Denis, J.L., Langley, A., \& Rouleau, L. (2010). The practice of leadership in the messy world of organizations. Leadership, 6(1), 67-88. doi: 10.1177/1742715009354233

Elmuti, D., Minnis, W., \& Abebe, M. (2005). Does education have a role in developing leadership skills. Management Decision, 43(7), 1018-1031. doi:10.1108/00251740510610017

Fairhurst, G. T. (2007). Discursive leadership: In conversation with leadership psychology. Thousand Oaks, CA: Sage.

Fairhurst, G. T. (2008). Discursive leadership: A communication alternative to leadership psychology. Management Communication Quarterly, 21(4), 510-521.

Fairhurst, G. T. (2009). Considering context in discursive leadership research. Human Relations, 62(11), 1607-1633. doi:10.1177/0893318907313714

Fairhurst, G. T. (2011). The power of framing: Creating the language of leadership. San Francisco, CA: Jossey-Bass.

Fairhurst, G. T. (2011). Discursive approaches to leadership. In A. Bryman, D. Collinson, K. Grint, B. Jackson \& M. Uhl-Bien (Eds.), The Sage Handbook of Leadership (pp. 495507). London, England: Sage.

Fairhurst, G. T., \& Grant, D. (2010). The social construction of leadership: A sailing guide. Management Communication Quarterly, 24(2), 171-210. doi:10.1177/0893318909359697

Fairhurst, G.T. \& Uhl-Bien, M. (2012). Organizational discourse analysis (ODA): Examining leadership as a relational process. The Leadership Quarterly, 23, 1043-1062. doi:10.1016/j.leaqua.2012.10.005

Fleishman, E. A. (1953). The measurement of leadership attitudes in industry. Journal of Applied Psychology, 38, 153-158. doi: 10.1037/h0063436 
Fletcher, R. B., \& Roberts, M. H. (2013). Longitudinal stability of the leadership scale for sports. Measurement in Physical Education and Exercise Science, 17(2), 89-104. doi:10.1080/1091367X.2013.761021

Foels, R., Driskell, J. E., Mullen, B., \& Salas, E. (2000). The effects of democratic leadership on group member satisfaction. Small Group Research, 31(6), 676-701. doi:10.1177/104649640003100603

Gamble, T.K., \& Gamble, M.W. (2013). Leading with communication: A practical approach to leadership communication. SAGE Publications: Thousand Oaks, CA.

Grint, K. (2000). The arts of leadership. Oxford, United Kingdom: Oxford University Press.

Gronn, P. (2011). Hybrid configurations of leadership. In A. Bryman, D. Collinson, K. Grint, B. Jackson \& M. Uhl-Bien (Eds.), The SAGE handbook of leadership (437-454). Thousand Oaks, CA: Sage.

Hackman, M.Z., \& Johnson, C.E. (2013). Leadership: A communicative perspective (6th ed.). Long Grove, IL: Waveland Press, Inc.

Hemphill, J.K. (1950). Relations between the size of the group and the behavior of superior leaders. Journal of Abnormal and Social Psychology, 32, 11-12. doi:10.1080/00224545.1950.9919026

Hersey, P., \& Blanchard, K.H. (1982). Management of organization behavior: Utilizing human resources (4th ed.). Englewood Cliffs, NJ: Prentice-Hall.

Humphrey, R. H. (2002). The many faces of emotional leadership. The Leadership Quarterly, 13(5), 493-504. doi:10.1016/S1048-9843(02)00140-6

Judge, T.A., Piccolo, R.F., Ilies, R. (2004). The forgotten ones? The validating of consideration and initiating structure in leadership research. Journal of Applied Psychology, 89, 36-51. doi: 10.1037/0021-9010.89.1.36

Katz, D., Maccoby, N., Gurin, G., \& Floor, L. (1951). Production, supervision, and morale among railroad workers. Ann Arbor: University of Michigan, Institute for Social Research.

Kellerman, B. (2008). Followership: How followers are creating change and changing leaders. Cambridge, MA: Harvard Business School Press.

Kotter, J. P. (2001). What leaders really do. Harvard Business Review, 71(11): 3 -11.

Liden, R. C., \& Antonakis, J. (2009). Considering context in psychological leadership research. Human Relations, 62(11), 1587-1605.

Madlock, P. E. (2008). The link between leadership style, communicator competence, and employee satisfaction. Journal of Business Communication, 45(1), 61-78. 
doi:10.1177/0021943607309351

Morrisette, S., \& Oberman, W. (2013). Shifting strategic imperatives: A stages of leadership perspective on the adoption of corporate entrepreneurship. Journal of Applied Management and Entrepreneurship, 18(2), 59-82.

Northouse, P. G. (2010). Leadership: Theory and practice (5th ed.). Thousand Oaks, CA: Sage.

Northouse, P. G. (2012). Introduction to leadership: Concepts and practice (2nd ed.). Thousand Oaks, CA: Sage.

Potter, J., \& Wetherell, M. (1987). Discourse and social psychology: Beyond attitudes and behaviour. Thousand Oaks, CA: Sage.

Putnam, L. L., \& Stohl, C. (1990). Bona fide groups: A reconceptualization of groups in context. Communication Studies, 41(3), 248-265. doi:10.1080/10510979009368307

Robles, M.M. (2012). Executive perceptions of the top 10 soft skills need in today's workplace. Business Communication Quarterly, 75(4), 453-465. doi:10.1177/1080569912460400

Ruiz, C. E., Wang, J., \& Hamlin, R. G. (2013). What makes managers effective in Mexico? Leadership \& Organization Development Journal, 34(2), 130-146. doi: 10.1108/01437731311321904

Schoel, C., Bluemke, M., Mueller, P., \& Stahlberg, D. (2011). When autocratic leaders become an option-Uncertainty and self-esteem predict implicit leadership preferences. Journal of Personality and Social Psychology, 101(3), 521-540. doi:10.1037/a0023393

Spreitzer, G. M., De Janasz, S. C., \& Quinn, R. E. (1999). Empowered to lead: The role of psychological empowerment in leadership. Journal of Organizational Behavior, 20(4), $511-526$.

Tannenbaum, R., \& Schmidt, W.H. (May/June, 1973). How to choose a leadership pattern. Harvard Business Review, 3-12.

Terzi, A. R. (2011). Relationship between power distance and autocratic-democratic tendencies. Educational Research and Reviews, 6(7), 528-535.

Tourish, D., \& Barge, J. K. (2010). An exchange of letters: What can a specifically discursive leadership perspective bring to bear on what must be one of the most studied subjects in human history? Management Communication Quarterly, 24(2), 322-347. doi: $10.1177 / 0893318909359698$

Tuleja, E.A., \& Greenhalgh, A.M. (2008). Communicating across the curriculum in an undergraduate business program: Management 100-Leadership and communication in 
groups. Business Communication Quarterly, 71(1), 27-43. doi:10.1177/1080569907312934

Uhl-Bien, M. and R. Marion (2011). Complexity leadership theory. In A. Bryman, D. Collinson, K. Grint, B. Jackson and M. Uhl-Bien (eds.). The Sage Handbook of Leadership. London: Sage 466-480.

Van Slyke, D. M., \& Alexander, R. W. (2006). Public service leadership: Opportunities for clarity and coherence. The American Review of Public Administration, 36(4), 362-374. doi:10.1177/0275074006293628

Warrick, D.D. (1985). Leadership styles and their consequences. Journal of Experiential Learning and Simulation, 3-4, 155-172.

Western, S. (2008). Leadership: A critical text. London, England: Sage.

Yip, J., \& Raelin, J. A. (2012). Threshold concepts and modalities for teaching leadership practice. Management Learning, 43(3), 333-354.doi:10.1177/1350507611422476

Yukl, G. (2010). Leadership in Organizations (7th ed). Upper Saddle River, NJ:Pearson.

Yukl, G. (2011). Contingency theories of effective leadership. In A. Bryman, D. Collinson, K. Grint, B. Jackson \& M. Uhl-Bien (Eds.), The SAGE handbook of leadership (286-298). Thousand Oaks, CA: Sage.

Zydziunaite, V., Lepaite, D., \& Suominen, T. (2013). Leadership styles in ethical dilemmas when head nurses make decisions. International Nursing Review, 60(2), 228-235. doi:10.1111/inr.12018

\section{Author Biographies}

Leah M. Omilion-Hodges (Ph.D., Wayne State University) is Assistant Professor in the School of Communication at Western Michigan University. Her research focuses on leadership and health communication within the larger context of organizational communication. Her work explores workgroup dynamics within applied settings to examine the influence of leadermember, peer, and team associations on relationship development, status distinctions, and sharing of resources. Her work has been featured in venues such as Communication Yearbook, Health Communication, and the Leadership Quarterly.

Stacey M. B. Wieland (Ph.D., University of Colorado, Boulder) is Associate Professor in the Department of Communication Arts and Sciences at Calvin College. She uses critical and qualitative approaches to study intersections between meanings of work, identity, culture, leadership, and organizations. She has published several journal articles and book chapters in venues such as Communication Monographs, Management Communication Quarterly, and Communication Theory. Her dissertation won the 2008 W. Charles Redding Dissertation Award 
from the International Communication Association, and her article "Ideal Selves as Resources for the Situated Practice of Identity" was Management Communication Quarterly's Article of the Year in 2010. 